\title{
Endoscopic retrograde appendicitis therapy: new approach in the treatment of stump appendicitis
}

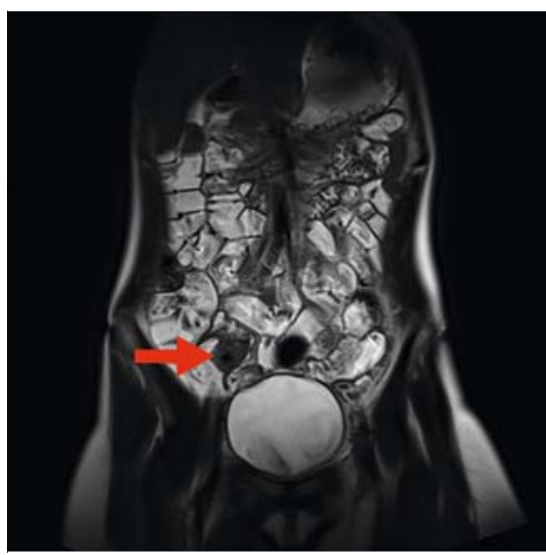

> Fig. 1 T2-weighted HASTE magnetic resonance image showed a spherical lesion with a diameter of $2.5 \mathrm{~cm}$ next to the ileocecal valve.

A 34-year-old woman presented at a primary care hospital with recurrent abdominal pain. Abdominal ultrasonography revealed a thickened terminal ileum with mesenteric wrapping and enlarged lymph nodes suggestive of Crohn's disease. A month earlier the patient had had appendicitis with subsequent laparoscopic appendectomy. On suspicion of Crohn's disease, the patient was started on budesonide $9 \mathrm{mg}$ once daily. As there was no clinical improvement after 3 weeks she was referred to our institution. Magnetic resonance imaging revealed a spherical lesion adjacent to the ileocecal valve (> Fig.1). Transabdominal bowel sonography identified a corresponding lesion in the right lower quadrant ( $\triangleright$ Fig. 2). At colonoscopy, the terminal ileum was normal, but a pseudotumor was apparent at the appendiceal orifice. The orifice was cannulated with a guidewire. Upon fluoroscopy, an appendicolith was detected in the stump of the appendix. The appendiceal orifice was dilated using a 10-mm through-the-scope balloon and the appendicolith was removed by inflation of a biliary extraction balloon ( $\vee$ Fig. $3 ;>$ Video 1 ). The patient was discharged without complications.

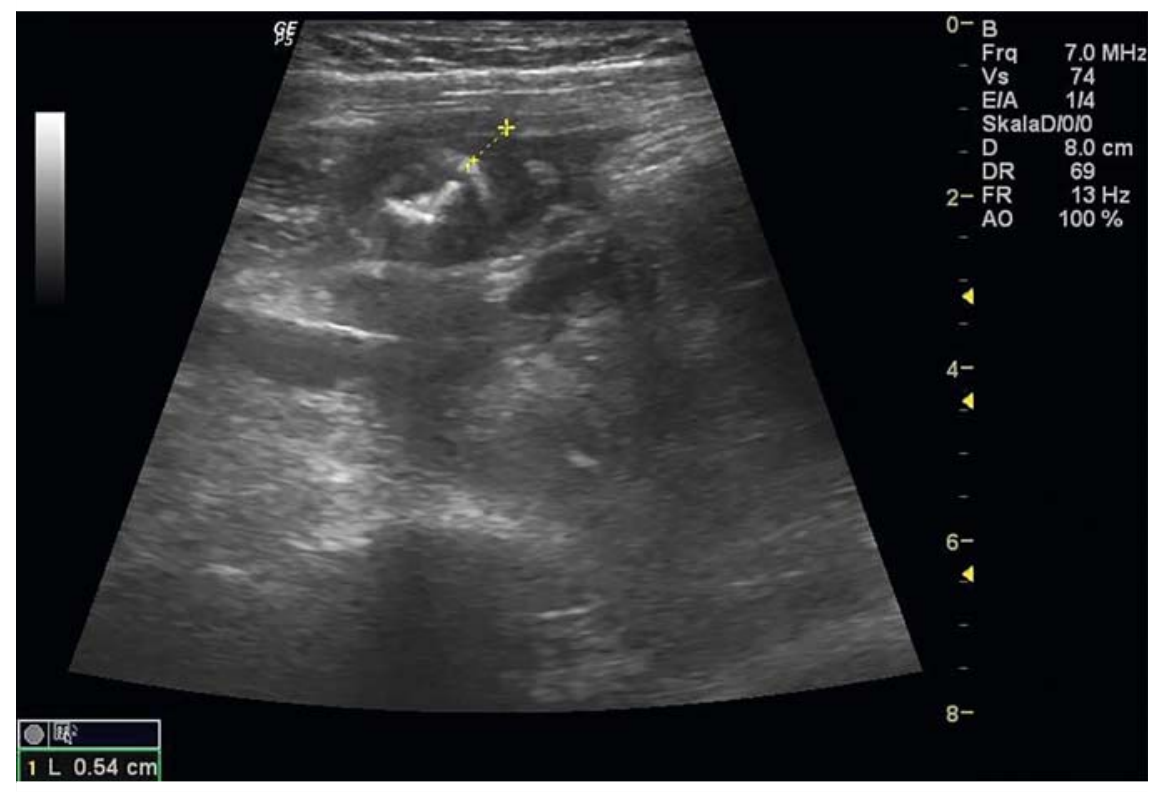

- Fig. 2 Transabdominal bowel sonography displayed a round hypoechoic lesion next to the ileocecal valve with $5 \mathrm{~mm}$ wall thickening and a calcified hyperechoic structure inside.
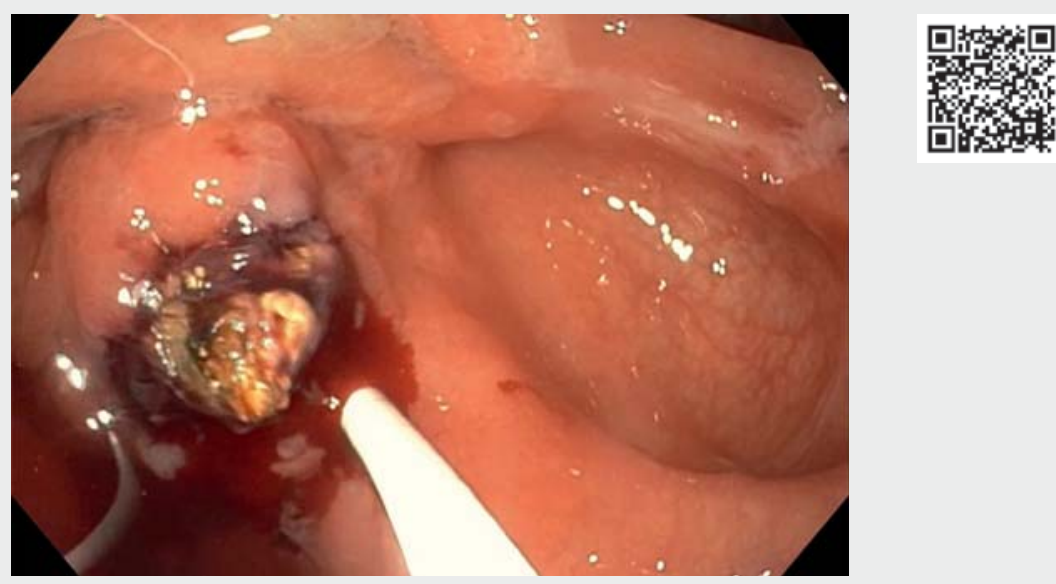

Video 1 Endoscopic removal of an appendicolith by balloon sweep.

An appendicolith is formed by mineral deposits and firm feces. It may lead to obstruction of the appendix, causing appendicitis. Yet, stump appendicitis after incomplete removal of such appendicolith is extremely rare. In our patient, a 1- to 2-cm appendiceal stump with associated appendicolith remained after laparoscopic appendectomy. Extensive inflammation or a partially or completely retrocecal appendix may lead to misidentification of the base of the appendix [1]. 

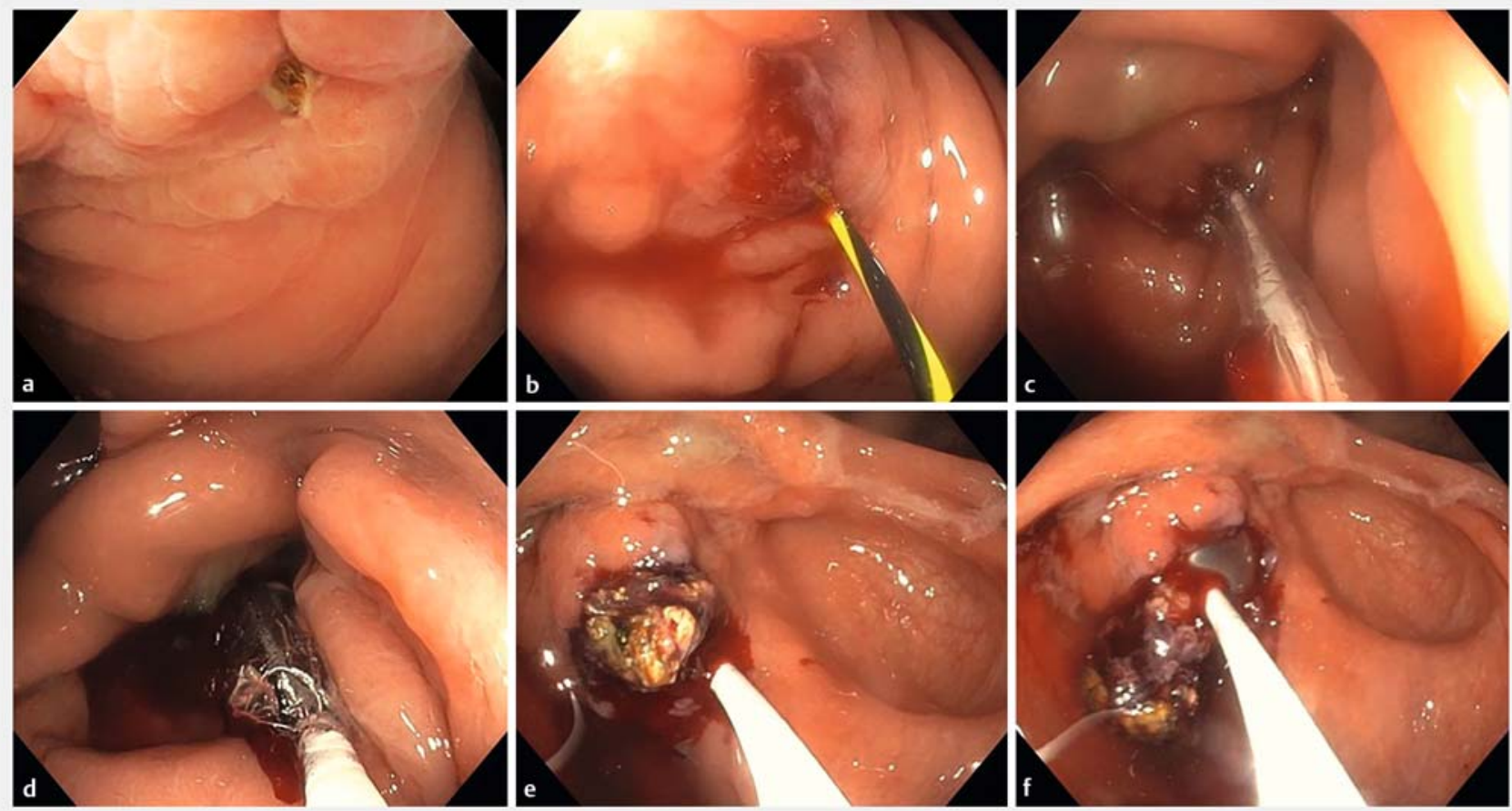

- Fig. 3 a Pseudotumor was apparent at the appendiceal orifice. b Cannulation of the appendiceal orifice using a guidewire was performed. c, $\mathbf{d}$ Dilation of the appendiceal orifice using a 10-mm through-the-scope balloon. e, $\mathbf{f}$ Removal of appendicolith by balloon sweep.

Endoscopic imaging of the appendix has been addressed in case series [2]. When appendicitis is caused by obstruction, such as appendicolithiasis, direct visualization of the appendiceal orifice and subsequent removal with retrieval balloon (e.g., endoscopic retrograde appendicitis therapy) is a feasible therapy [3], although knowledge of variations in cecal anatomy and endoscopic landmarks is required. Nevertheless, when cannulation is feasible the natural orifice approach is a legitimate option.

Endoscopy_UCTN_Code_TTT_1AQ_2AF

\section{Competing interests}

The authors declare that they have no conflict of interest.

\section{The authors}

\section{Felix Haller ${ }^{1}$, Christoph Gasche ${ }^{1,2}$}

1 Division of Gastroenterology and Hepatology, Internal Medicine III, Medical University of Vienna, Austria

2 Loha for Life, Vienna, Austria
Corresponding author

\section{Christoph Gasche, MD}

Division of Gastroenterology and

Hepatology, Internal Medicine III, Medical

University of Vienna, Währinger Gürtel 18 ,

Vienna, Austria 1090

christoph.gasche@meduniwien.ac.at

\section{References}

[1] Roberts KE, Starker LF, Duffy AJ et al. Stump appendicitis: a surgeon's dilemma. J Soc Laparoendosc Surg 2011; 15: 373-378

[2] Ferlitsch A, Puespoek A, Gasche C. Endoscopic imaging of the vermiform appendix (with video). Gastrointest Endosc 2014; 80: 1156-1160

[3] Costamagna G. Acute appendicitis: will a novel endoscopic "organ-sparing" approach change the treatment paradigm? Gastrointest Endosc 2020; 92: 190-191

\section{Bibliography}

Endoscopy 2022; 54: E15-E16

DOI 10.1055/a-1346-8677

ISSN 0013-726X

published online 16.2.2021

(c) 2021. Thieme. All rights reserved.

Georg Thieme Verlag KG, Rüdigerstraße 14, 70469 Stuttgart, Germany

\section{ENDOSCOPY E-VIDEOS \\ https://eref.thieme.de/e-videos}

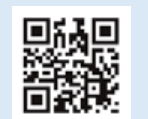
Endoscopy E-Videos is a free access online section, reporting on interesting cases and new techniques in gastroenterological endoscopy. All papers include a high quality video and all contributions are freely accessible online.

This section has its own submission website at

https://mc.manuscriptcentral.com/e-videos 